\title{
Proceeding
}

6th INSHS International Christmas Sport Scientific Conference, 11-14 December 2011. International Network of Sport and

Health Science. Szombathely, Hungary

\section{School internment and physical education in vocational schools}

\author{
JOËL GAILLARD \\ Faculty of Sport, Université Henry Poincaré, France
}

\begin{abstract}
Gaillard J. School internment and physical education in vocational schools. J. Hum. Sport Exerc. Vol. 7 , No. Proc1, pp. S103-S115, 2012. School failure is a process where a student slips further and further behind his peers and gradually disconnects from the educational system. The end result of school failure is dropping out before graduation. Dropping out of school is therefore not an isolated phenomenon of learning failure. It is, like social exclusion, related to a multitude of social, health, family and financial factors. Although school failure is only one consideration in a larger "domino effect" of social deprivation, dropping out of education is often the fatal stumbling block that deprives young people of skills, qualifications, purpose and order in life, as well as the social contacts and environment they need in order to be listened to and appreciated. Some of those students are not particularly attracted by success, but neither are they concerned about failure. We have identified an Emergence of some resentment associated with a possible feeling of "school internment"... "state into which he locks itself (or is locked) in a long-lasting way the pupil following a school course which brings him to adopt certain numbers of characteristics behaviours allowing him or he) to resist to the suffering caused by the distance between the expectations of school and of its own aspiration. This state leads him or her to the danger of not obtaining the diploma and thus risking the professional and social exclusion". It seems as if the pupils came there just to be right with the school, without however being fully aware of its values and cognitive schemes. Things go on as if they only tried to postpone the verdict of school failure, though not really hoping to escape from it. The discussions are intended to examine the effects of sport practices at school and determine how Physical Education can appear as an answer to the academic failure, thus to the "school internment" because it proposes a "third mediating place". Key words: ROTATION, ABILITY, PSYCHOLOGICAL CONFINEMENT, SELF-ESTEEM, PROFESSIONAL HIGH SCHOOL, SCHOOL INTERNMENT, VIOLENCE, LANDMARK, MENTAL REPRESENTATION, PERCEPTION.

Corresponding author. LISEC EA 2310, Faculty of Sport Nancy. France.

E-mail: joel.gaillard@staps.uhp-nancy.fr

6th INSHS International Christmas Sport Scientific Conference, 11-14 December 2011. International Network of Sport and Health Science. Szombathely, Hungary.

JOURNAL OF HUMAN SPORT \& EXERCISE ISSN 1988-5202

(c) Faculty of Education. University of Alicante

doi:10.4100/jhse.2012.7.Proc1.12
\end{abstract}




\section{INTRODUCTION}

At first analysis, "comprehensive schools" ( $70 \%$ of incidents according to " signa » software) are the most violence affected institutions. But if we relate this figure to the number of students, Vocational Schools appear to be as highly concerned places. The recent report "Violence in college and high school students: assessment and developments" directed by Marie Choquet, Christine Hassler and Delphine Morin, data from the ESPAD survey (European School Survey Project on Alcohol and Other Drugs) confirms this. It also indicates a disturbing and worsening situation for young people enrolled in vocational school.

This article highlights an unspectacular and little covered form of violence: "School Internment". The data presented here come from an academic paper recently published in "Chronique Sociale". The specific phenomenon of targeted violence at vocational schools should be considered within its own context. This article does not limit itself only to the clinical description of this ill being at school. In a second section, it presents an original educational experiment currently underway in a vocational school in the department of Moselle set up specifically to try to stop this invisible noiseless and specific violence escalating.

\section{A noiseless and deaf violence: School internment}

Students enrolled in vocational school rarely get there by choice. Most of them have sustained chaotic and difficult educational paths. Some of these students have gone through special education classes or preapprenticeship before ending up in these particular sections preparing Vocational Training Certificate. They prepare a degree which is not valued by the world of work and the social hierarchy. Roger Perron names it "first recognized social flop." But the certificate is their last chance before an announced exclusion before a future strewn with pitfalls, more or less successful returns in subsequent courses. Serge Paugam (2000) notes that "if at the end of the school the risks of decommissioning are important to the least qualified, including holding a CAP or BEP, they are even more so for those who are deprived of any qualification and/or any degree"

Faced with cognitive, behavioral, social and / or family difficulties, parts of the CAP students are threatened by decline and isolation. While claiming a membership of school, they are sometimes unable to produce a minimum of academic work; which let them run the risk of leaving school without any diploma. This situation that the students themselves describe as "prison" or "labour camp" invites us to turn to the legal vocabulary and to define their school experiences as a situation of confinement. These students are sitting on the fence, half way between inclusion and exclusion. In response to a standard and an often intense social and/or family pressure, they go to school but they go less to learn and acquire knowledge than to meet friends, to live in a compliance report and leaving no one in doubt a pupil's sense of belonging.

Dominique Glasman describes their situation as "cognitive dropping out" This is in fact the result of a long and slow process in which a form of cognitive inferiority is established. Indeed, gradually learning difficulties generate a phobia towards school work, which freezes capacity and leads them to "choose" the posture of a bad student. Step by step these students have built around them a kind of fence that prevents access to knowledge and, more broadly, access to the Tools for understanding school expectations. Such an experience is not lived through without suffering. Total loss of confidence, recorded "in a report to the indefinite future," the reclusive pupil afraid of not knowing reinvest their knowledge and fear of being unable to find its place in the world of work. 
He has internalized a negative identity and integrated over time the idea that he is worthless and that "school's expectations" are not made for him. He believes that he has no ability and therefore shall not commence anything while many tasks are within his reach. We are close to what Seligman calls "learned helplessness" and that we will for our part name as "school internment" which is the "state into which he locks itself (or is locked) in a long-lasting way the pupil following a school course which brings him to adopt certain number of characteristics behaviours allowing him or her to resist to the suffering caused by the distance between the expectations of the school and of its own aspiration". It is the negative consequence of experiences ending in failure so entailing the relinquishment of any effort [...], it is the consequence of the perception of a chronic absence of control and power over the events.

School Internment is not a reflection of human nature but the result of a history, the temporary end of a path due to failure and worthlessness. The "recluse student" is resigned, discharged, as if retreating into himself. If he has no more hope it is because he has given up hope over himself. Stuck between a present of which he does not perceive the issues and a future that seems jammed, he waits without really knowing what he wants. The main feature of this is the feeling of being unable to turn the tide. Hence this inability, this irresoluteness characterizing of the recluse student, he really doesn't wish to stay at school but wants to leave even less, he will no longer enter the world of work (and still less join the working world ... that he sees as a world of pressure and obligations.).

\section{School: a paradoxical place}

If school status generates suffering and a feeling of worthlessness, anxiety raised by the risk of "marginality, potential and/or real exclusion" still encourages "resigned students" to remain cloistered within the school. Leaving it involves introducing a degree of change into his live. Excluded, resigned, dropouts, reclusive, are categories which should not be comprehended too wide and should not be also reduced to the minimum. A "Recluse student" rejects school and often does it ostentatiously and aggressively. He has moved into other places, other networks (group of friends, odd jobs ...), which "allow" him to state furiously his intolerance of school. The resigning student wants to end a spiral of failure and suffering; he often retreat into a fallback career plan. If the resignation is tinged with bitterness or regret, it is also experienced as a relief. Generally, the socio-familial supports and enables it. The "recluse's" suffers but the family and/or social environment does not allow him to leave school, it forces him to hide his difficulties.

The "recluse's" has school as main reference. This is the place to create networks of friendship. Aziz Jellab (2003) presenting the results of a survey of students enrolled in CAP and BEP in the department of Pas-deCalais as written notice that the students "refer only to reports of sociability, without any reference of school knowledge." School is also the place that can claim a social identity (be student) is the place where he finally has something to do even if it is not always able to fulfil them. School is the place where impotence paradoxical school and some form of social recognition and forge ties with strange experiences

François Dubet, Olivier Cousin and Jean Philippe Guillemet defining school "as a space where social culture, class culture and school culture run into each other's" show that student attitudes are branch of the distance between these cultures and the systems available they require and they generate."The recluse's" experienced the distance between these different systems, the incompatibility between these different spheres of influence. When schooling, the "recluse's" rejects the world he has always devalued cause the tensions between the expectations of school and his inability to answer. Paradoxically, however, that safe environment, as known, remains the only possible refuge as long the world of work it seems inaccessible. 
These difficulties sometimes may obscure the awareness of the necessity to be qualified to start a career. "School Internment" appears as the only possible way, face to the suffering engendered by school expectations. Family and personal stories often help to amplify these students in a reclusive attitude. They are also encouraged by peers or family members who also have decoded school through the suffering it inflicted on them. These students are trained but are not involved, without rejecting it, without leaving it, they are at school. They do not fulfil their assignment but are nevertheless unable to leave the academic world.

School needs to support these students, so energetic and inventive. If school needs to educate and train students it accepts, it is also, in another way, in charge of the future of those who leave it.

Face to a history of failing, they have a low sense of self-worth and are not very confident of their ability to succeed academically. As a result, they may develop a maladjusted behavior, focusing more on the fear of failure than on striving for success. These students are negatively motivated by the fear of failure and the anticipation of shame in response to a failed effort. To avoid the shame and emphasis of apparent low ability, they limit their effort expended. Sometimes their fear of failure leads them to strive very hard to succeed, which they often do. Their success is precarious because small setbacks can have lasting effects. Because of the emotional significance of failing, they often experience test anxiety. Rather than openly limiting effort, they often engage in self-handicapping behaviors such as procrastination, and they provide an excuse for poor performance. They rationalize that these are the factors that kept them from succeeding thus protecting an already tenuous sense of self-worth. These pupils are not particularly attracted to success, but neither are they concerned about failing

\section{MATERIAL AND METHODS}

\section{Framework}

-Questionnaires: 734 students (out of a total of 863 students-return rate: $85.6 \%$ ) who had failed to pass their first year at primary school now studying in a vocational school (74 schools)

- Interviews: 34 students who had been chosen among the 538 for their contrasted profiles on some of the variables investigated in the questionnaire. They were interviewed twice.

\begin{tabular}{|l|r|r|}
\hline \multicolumn{1}{|c|}{ sexe } & Nb. cit. & \multicolumn{1}{c|}{ Fréq- } \\
\hline Fille & 311 & $42,1 \%$ \\
\hline Garçon & 427 & $57,9 \%$ \\
\hline TOTAL OBS. & $\mathbf{7 3 8}$ & $\mathbf{1 0 0 \%}$ \\
\hline
\end{tabular}

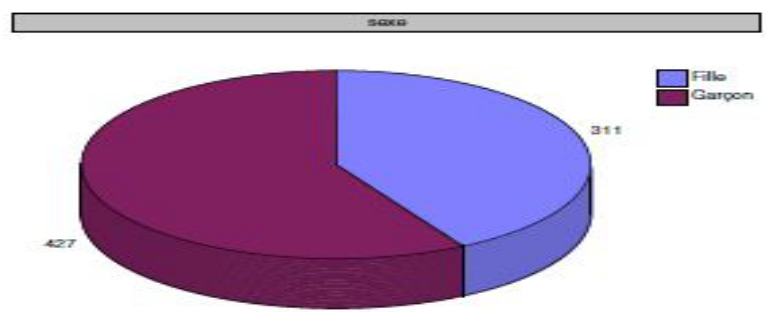

Figure 1. Number of male - female. 
Adapted general and professional schooling programmes, defined in 1990 and implemented by Circulars no. 98-129 (19/06/1998) and no. 2006-139 (29/08/2006), are available to students with serious and persisting schooling difficulties. These programs, which are designed to provide professional qualifications, are implemented in different types of institution:

-The adapted general and professional schooling sections (SEGPA), successors to the specialised education sections created by Circular no. IV-67-530 (27/12/1967). Integrated into ordinary secondary schools, the purpose of these sections was redefined after 1989, leading to significant reinforcement of schooling programmes.

-The regional adapted schooling establishments (EREA) replace the national further education schools created by Law no. 51-1487 (31/12/1951). Circular no. 95-127 (17/05/1995) required the EREA to become adapted learning high schools (LEA), but was never implemented. Most of the EREA provide boarding and host adolescents who evidence serious learning and social difficulties. However, some establishments also provide tuition to sensory or motor disabled youths capable of following secondary level classes.

-The UPI created by Circular no. 95-125 (17/05/1995) for the inclusion of children with mental disabilities. Circular no. 2000-009 (13/01/2000) extended the competence of UPIs to all disabilities or illnesses. Circular no. 2001-035 of February 21, 2001 on schooling of disabled students in secondary schools and the development of UPIs, replaces previous circulars and defines the framework for schooling of disabled students with serious cognitive function disorders in secondary schools, extending inclusion in the programme to students with sensory or motor disabilities and advocating the development of UPIS at the secondary level, including vocational training schools.

Most of them are coming from adapted schooling

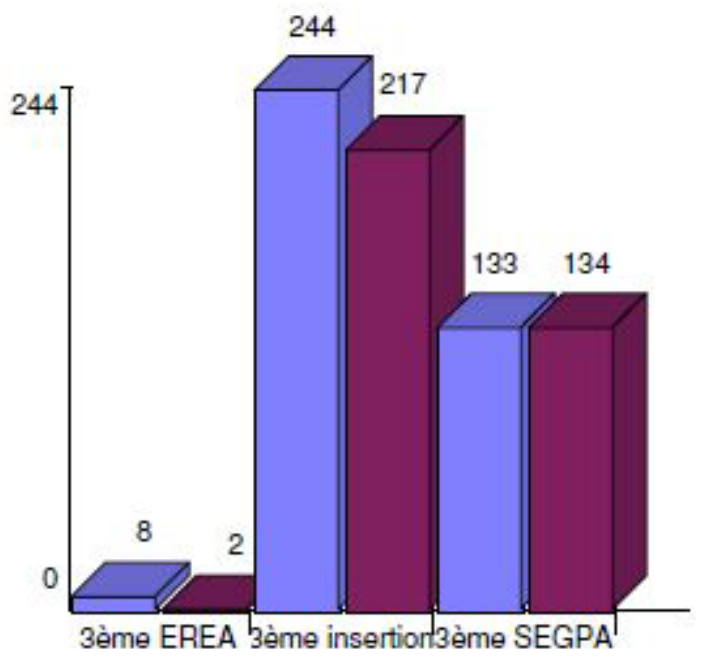

Figure 2. Origin of students. 
Although each cycle normally lasts three years, it can be completed in two or four years, depending on the child's progress. The decision whether a child is ready to progress to the next cycle is made jointly by a teachers' council, the school director, the pupil's teachers and a psycho-pedagogical group. It's no longer possible to fail a year and have to repeat it, as the new system allows pupils to progress at their own speed and doesn't require them to repeat the same work as in the previous year. Parents are able to appeal against a school's decision regarding progression to the next cycle. A school year record book is maintained for each child during the three cycles.

\section{RESULTS}

They all have repeated one two or three classes

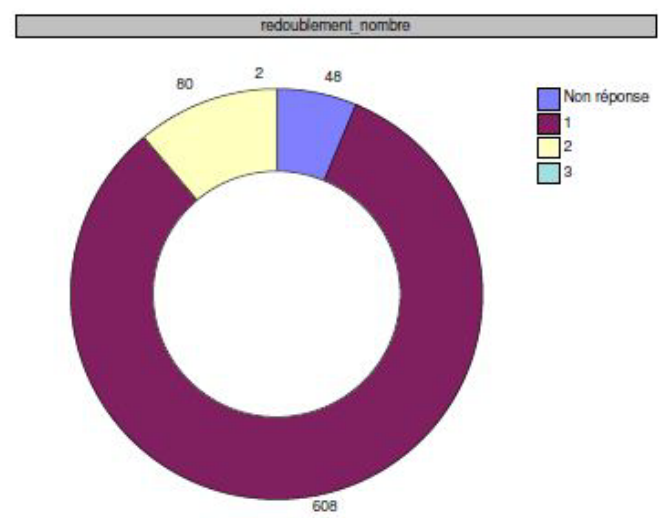

Figure 3. Number of classes repeated.

Most of them don't know why they are going to school:

\begin{tabular}{|l|r|r|r|}
\hline $\begin{array}{c}\text { Col sais pas pourquoi } \\
\text { sexe }\end{array}$ & non & \multicolumn{1}{c|}{ oui } & TOTAL \\
\hline Fille & 281 & 30 & 311 \\
\hline Garçon & 384 & 43 & 427 \\
\hline TOTAL & 665 & 73 & 738 \\
\hline
\end{tabular}

La différence des répartitions entre 'non' et 'oui' n'est pas significative

(chi2 $=0,04,1-\mathrm{p}=15,11 \%$ )

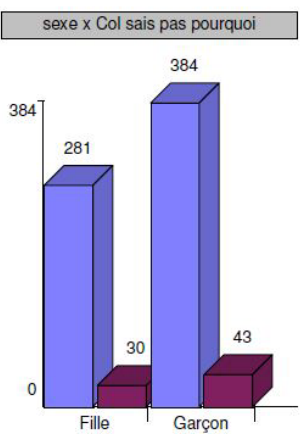

$\square$ non $\square$ oui

Figure 4. Know why they stay at school or not. 


\begin{tabular}{|l|r|r|}
\hline Frpq pas capable & Nb. cit. & Fréq. \\
\hline non & 407 & $55,1 \%$ \\
\hline oui & 331 & $44,9 \%$ \\
\hline TOTAL OBS. & 738 & $100 \%$ \\
\hline
\end{tabular}

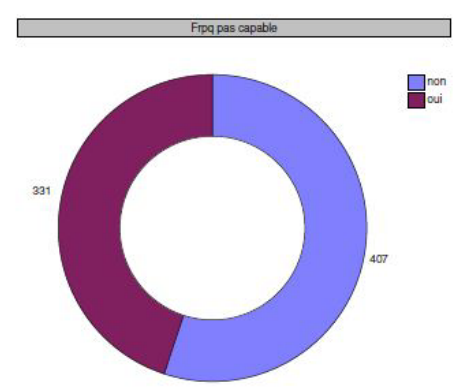

Figure 5. Feel able or not.

It seems that there is a lag time between the difficulties and frustrations and their transgressive events as if they required that students feel at ease and confident.

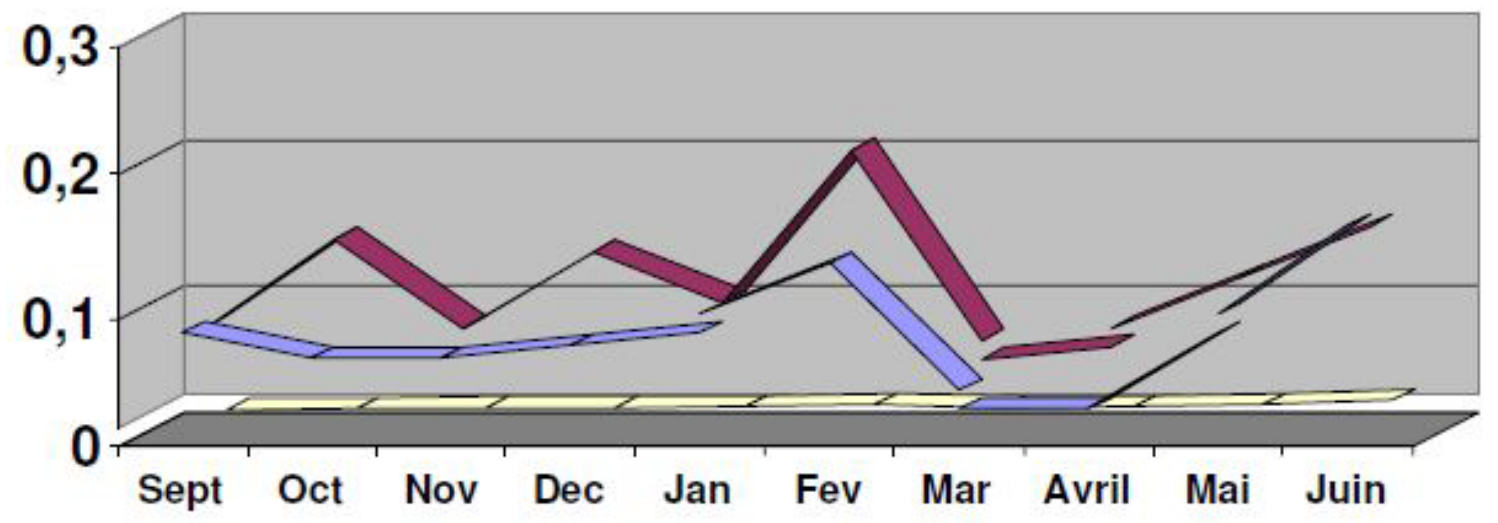

Figure 6. Absenteeism. 
Many vocational schools, have a high rate of absenteeism, significant delays and micro-violence tended to trivialize it. The student absenteeism generally follows an upward trend until the school holiday periods and renewed in the same way after them. The evolution curves that consider the period September to March, (date of departure to the first Work Placement) in April and return date to the summer shows that student absenteeism High School is located at around 0.1 while that of students in CAP is around 0.2. The student absenteeism CAP is twice as high as in average of high schools.

When you can do here something surprising you?

This is the limit ... the void may be invisible.

Invisible?

Yeah ... I do not know ... they do not see me ... they do not talk to me ... it's as if I did not exist ... they do not mind me ... I know just buddies from last year ... it's in the classroom or in the yard, in fact ... I feel ... uh ... be rejected not rejected ... invisible ... they do not see me ...

What does it makes you?

I do not know ... I would like to see me ... that somebody speaks to me a little more ... I feel a little lonely isolated said.

Feeling "school internment" these students are adopting various co-existing behaviours and ongoing features:

-Refusal to respond at School expectations.

-Non-involvement in school life.

-Inability to gather one's thoughts.

-Inability to set to work.

-Inability to complete a task.

- Lack and/or absence of motivation face to school proposals.

-Rush to complete a task to get ride of school expectation.

-Numerous Lateness's.

-Restless.

- Clashes with professors or other students.

-Involvement in events sanctioned by a deduction or a small suspension and/or expulsion.

- Circumstances such as truancy.

-School apathy.

-Inattention.

Some dominant features let show some psychological profile: 
-Student, who suffers the course, never takes the floor.

-Troublemaker face to others (student or teacher) without exceeding limits, however, never could do exclude.

-The student who, although present, doesn't work.

-Absenteeism (within no more than that to avoid being excluded).

-The regression ("mothering" and "paternage")

-The denial (contesting of the judgment of teachers, dispute their educational skills).

-The inhibition (defense against what hurts)

-The insulation (defensive armour plating which eliminates the emotional proceed of the school endeavor)

The movement (bonuses in the other activities: sport, clown, "boss" of the school, delinquency).The fantastical compensation (school apathy, compensatory fantastical life like Dragon Ball, Lorie).

We can resume this particular behaviour with the following diagram

\section{School Internment Process}

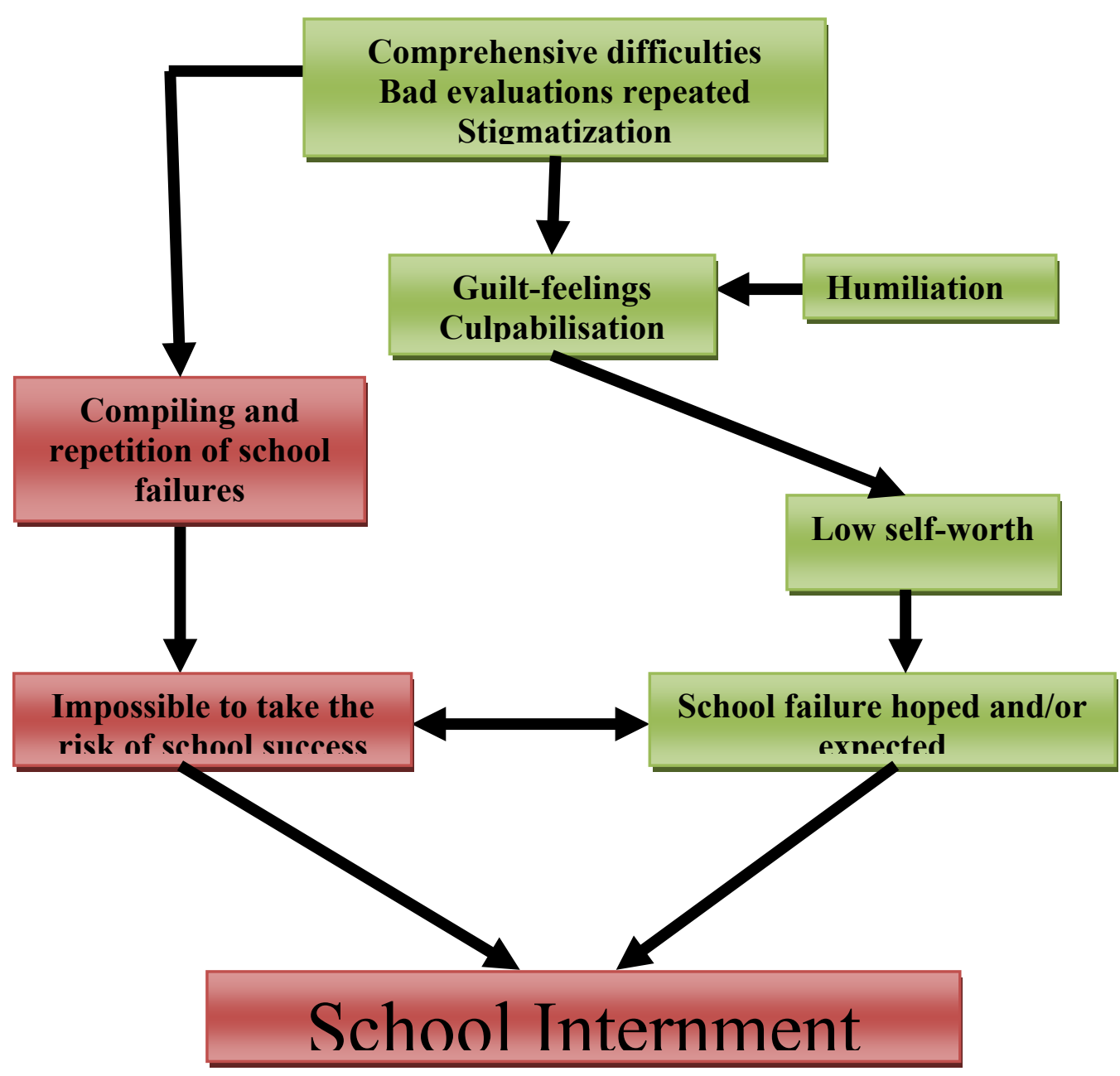


It seems as if the pupils came there just to be in keeping with the school, without however being fully aware of its values and cognitive schemes. Things go on as if they only tried to postpone the verdict of school failure, though not really hoping to escape it.

Wayne and Youngs (2003) examined ratings of teachers' undergraduate institutions, teachers' test scores, degrees and coursework, and certification status. They concluded that "students learn more from teachers with certain characteristics.... Teachers differ greatly in their effectiveness, but teachers with and without different qualifications differ only a little" (p. 100-101). Berry (2002) posits that while these teacher qualities are indeed important they appear to have a "singular focus on content knowledge" (p.1). Highly qualified teachers must also know "how to organize and teach their lessons in ways that assure diverse students can learn those subjects...Highly qualified teachers don't just teach well-designed, standards-based lessons: They know how and why their students learn..."(p.2). The literature on teacher characteristics makes a strong case for highly qualified teachers. Having over 60 years of teaching experience among us, the authors of this article found supporting data in a very unassuming place-from out students. At the beginning of the school Year, we have asked our high school students' one question:

What is it about your favorite teacher that made them teachers from whom you were able to learn?

The answers are not surprising. One's of the most evocated teacher is PE Teacher; In fact most of them trust their PE Teachers (13.1\%).

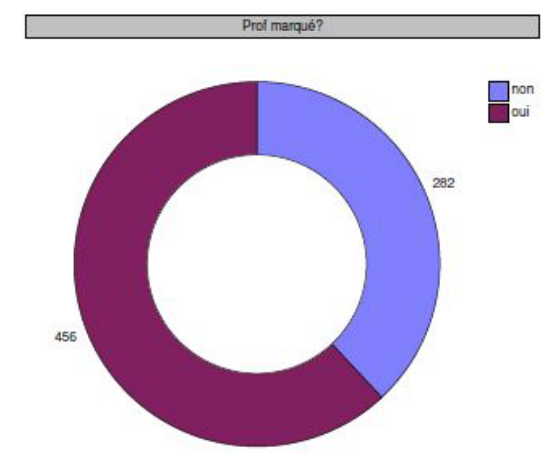

Figure 7. A Teacher was important. 
It seems to us that they don't trust the school system and particularly the teachers

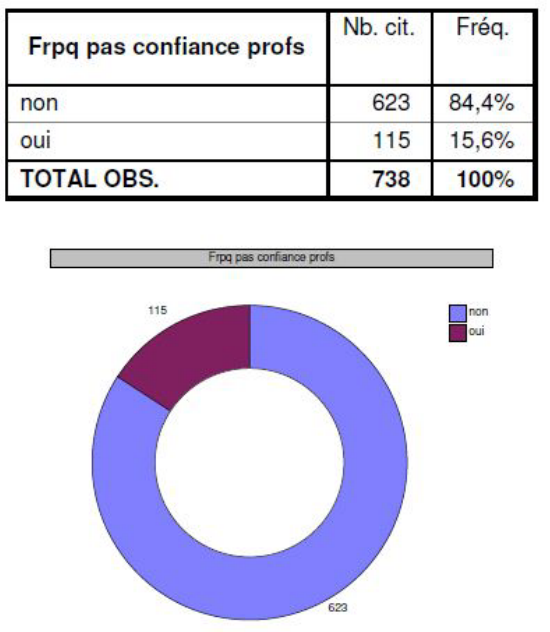

Figure 8. Trust in teacher or not.

\section{DISCUSSION}

\section{Climbing as a mediate}

Physical education programs have the responsibility to teach skills that students will need to participate in physical activity outside of the physical education class and skills they will need for a lifetime of physical activity.

The organized sport in school is an opportunity to deflect the initially directed self aggression, to the school competition. Sport activities generating exclusion appear to be a display of aggression related to the syndrome of death. To propose a different framework, other practices where sport would "neither nor" or alienating or liberating, neither good nor bad. It should be possible to claim the right to pleasure, the right to immobility, laziness, to get out of the race performance that leads to the "school internment" students who cannot consider their courses from a long term perspective.

The study of the relationship to knowledge and bodily practices in physical education classes, especially climbing, reveals ways of learning that can help us to understand how the process of failure or success in physical education are going on.

Learning despite adversity; learning because it is very good and it's mediated by peers and teachers, refusing to learn because we already know everything and do not think we need to learn more, not learning because peers do not let them do, refusing to learn because they exclude themselves, these are some examples we observed in progress.

Once in contact with the bodily practice, these motives can be renewed when the student identifies the contents but also the function that it can have in life. Learning of this knowledge may be related to entertainment, but also professional future, but it will always be in the expectation that the content meets a lack of respect. 
Besides the wealth of proposed acquisitions drive, climbing, by the presence of risk, engages students in the whole of their person. Be limited to motor and cognitive dimensions of student activity would be denying the essence of climbing.

We must emphases that the affective dimension is sought, particularly in phases of destabilization of the student, when his resources no longer allow him to manage the condition. Activity demanded total commitment requires consistent work against anguish, his narcissism, the exact state of one's inner resources. On a formal level, resources can be mobilized out of school context. Didier Delignères emphasizes the issues covered by this emotional connection to the physical activities by evoking the use that is made for purposes of rehabilitation or social reintegration. Control of risk develops self-esteem and feeling of competence.

Jean-Claude Castagnino mentions an observation of high school students by Jean Yves Bort. The results shows that the risk, originally designed as a breach of security imposed by the educational environment, gradually becomes a value, a tool which open the world, a way to discover new limits: venture to transformation.

The cognitive activity of the climber "recluse" is not a progressive denial of his emotions, but a contribution to the learning of their knowledge and their control. In this sense, escalating contributes to what some researchers call Anglo-Saxon emotional intelligence (Goleman, 1996). The ability to judge the student (read and agree to undertake the risk and success) develop self-confidence and sense of competence.

It is in our view in the consideration of the overall commitment of these students in learning activities that the treatment of physical education (what content to what audience?) and reading "in vivo" of these students alternating activity as we propose will be a field for students out of "school internment".

\section{CONCLUSIONS}

The three-dimensional balanced time table fits well within the framework of compulsory education; it is another way of organizing the year by multiplying the opportunities to dedicate themselves thoroughly to the job at hand and to put oneself into school. Allowing students to decipher the reclusive world, helping to change the look he is on it and himself, that is the challenge.

School Internment may be an opportunity to resume the meditation proposed by Ivan Illich (2003) in the seventies. Ivan Illich (2003) called into question not the school form in itself, but its excesses and the risk that beyond a certain threshold, it becomes cons-productive, that is to say a factor of exclusion, alienation and inequality. If this thesis encloses a grain of truth then the scenario can become a dropout on some public an appropriate response, a paradoxical way to give a new chance at school and a new horizon for students in distress.

\section{REFERENCES}

1. BERRE B. What it means to be a "highly qualified teacher. Southeast Center for Teaching Quality, 2003.

2. BETTENCOURT E, GILLETT M, GALL M, \& HULL R. Effects of teacher enthusiasm training on student on-task behavior and achievement. American Educational Research Journal. 1983; 20. 
3. BLOCH MC, GERDE B. (sous la dir). Les lycéens décrocheurs, de l'impasse aux chemins de traverse. Lyon, Chronique Sociale; 1998.

4. CHARLOT B, BAUTIER E, ROCHEX JY. École et savoir dans les banlieues ... et ailleurs. Paris, A. Colin; 1992.

5. CHARLOT B. Du rapport au savoir. Eléments pour une théorie. Paris, Anthropos; 2002.

6. CRUICKSHANK DR, JENKINS DB, \& METCALF KK. The act of teaching. New York. NY:McGrawHill; 2003.

7. DUBET F, COUSIN O, ET GUILLEMET JP. Sociologie de l'expérience lycéenne, Revue Française de pédagogie; 1991.

8. DUBET F. Sociologie de l'expérience. Paris, Seuil; 1994.

9. DUBET F. Les Lycéens. Paris, Seuil; 1991.

10. DURU-BELLAT M, VAN ZANTEN A. Sociologie de l'école. (2ème éd.), Paris, Armand Colin; 2002.

11. GAILLARD J, KERNER I. Repenser l'alternance en lycée professionnel. De la réclusion scolaire à la remotivation. Lyon, Chronique sociale; 2005.

12. GUILLAUMIN C. Une alternance réussie en lycée professionnel. Paris, L'Harmattan; 1997.

13. ILICH I. Une société sans école. Paris, Seuil, Coll. Points Essais; 2003.

14. JELLA B. Entre socialisation et apprentissages: les élèves du lycée professionnel à l'épreuve des savoirs. Revue Française de pédagogie. 2003; (142).

15. PAUGAM S. La disqualification social. Paris, PUF; 2000.

16. RICE JK. Teacher quality: Understanding the effectiveness of teacher attributes. Washington, D.C.: Economic Policy Institute; 2003.

17. RICOEUR P. Le juste. Paris, Editions Esprit; 1995.

18. VAN ZANTEN A. (sous la dir.) l'École, L'état des savoir. Paris, La Découverte; 2000.

19. WAYNW AM, YOUNGS P. Teacher characteristics and student achievement gains: A review. Review of Educational Research. 2003. 